\title{
TRANSPLANTE DENTAL AUTÓGENO COMO ALTERNATIVA À REABILITAÇÃO ORAL
}

\author{
AUTOGENOUS TRANSPLANTATION DENTAL AS ALTERNATIVE TO ORAL REHABILITATION
}

\author{
Rafael Lopes Quadros da SILVA'; Caio de Andrade HAGE²; Thais da Silva FONSECA ${ }^{3}$; Diego Pacheco FERREIRA ${ }^{4}$ \\ 1 - Residente em Cirurgia Traumatologia Buco-maxilo-facial pelo Hospital Universitário João de Barros Barreto da Universidade Federal do Pará. \\ 2 - Especialista em Cirurgia e Traumatologia Buco-maxilo-facial pelo Hospital Universitário João de Barros Barreto da Universidade Federal do Pará. \\ 3 - Graduanda em Odontologia pela Universidade Federal do Pará; Estagiária do Serviço de Cirurgia e Traumatologia Buco-maxilo-facial do \\ Hospital Universitário João de Barros Barreto da Universidade Federal do Pará. \\ 4 - Cirurgião e Traumatologista Buco-maxilo-facial pelo Hospital Universitário Pedro Ernesto da Universidade do Estado do Rio de Janeiro; Staff da \\ Residência em Cirurgia e Traumatologia Buco-maxilo-facial do Hospital Universitário João de Barros Barreto da Universidade Federal do Pará.
}

\section{RESUMO}

Objetivo: Reportar um caso clínico de transplante dentário autógeno associado à contenção com fio de sutura e descrição dos passos cirúrgicos. Materiais e métodos: Um indivíduo submetido a transplante de terceiro molar inferior para um alvéolo de primeiro molar inferior com comprometimento de erupção por dilaceração radicular avançada, através de exodontia pela técnica de incisão em envelope, seguido de contenção com fio de sutura por um período de uma semana. Resultados: $\mathrm{O}$ dente transplantado obteve satisfatória acomodação no novo alvéolo, uma vez que ao acompanhamento de 12 meses apresentou seguimento da rizogênese, ausência de bolsas periodontais, anormalidade pulpar e inexistência de mobilidade dentária. Conclusões: Perante a técnica cirúrgica utilizada e indicações adequadas, observou-se terapêutica de baixo custo e biologicamente viável - por não comprometer o seguimento da formação radicular como solução em caso de reabilitação oral.

Palavras-chave: Transplante autólogo; Extração dentária; Cirurgia bucal; Maxila.

\section{INTRODUÇÃO}

O transplante dentário é uma opção de tratamento para reposição de elementos dentários quando há um dente doador viável, podendo ser indicado em casos de dentes inclusos, agenesia dental e perda prematura de dentes devido a trauma, cárie ou doença periodontal ${ }^{1,2}$. O momento ideal para a realização deste procedimento é quando o dente atinge de metade a três quartos do comprimento radicular, e o forame apical está aberto, para que o término da rizogênese aconteça no leito receptor ${ }^{1-3}$ deste modo provavelmente não sendo necessário o tratamento endodôntico. A execução cirúrgica dos transplantes dentais, por ser biologicamente viável e as experiências até agora alcançadas, faz incentivar uma utilização mais abrangente do método para resolver problemas associados à reposição de dentes com indicação de extração.

O exame imaginológico, bem como a radiografia periapical, são imprescindíveis na seleção e indicação da cirurgia, principalmente para estabelecer o estágio de formação radicular, o diâmetro mésio-distal do dente a ser transplantado e as possíveis patologias no sítio cirúrgico ${ }^{1-3}$.

A taxa de sucesso de dentes autógenos transplantados varia entre $68 \%$ a $96 \%^{4}$, no entanto, um bom prognóstico do transplante depende de requisitos específicos do paciente, do dente doador e do sítio receptor. Os pacientes precisam ter boa saúde geral, serem aptos para seguirem as instruções pós-operatórias e demonstrarem um aceitável nível de higiene oral ${ }^{2,4}$. Além disso, deve existir um adequado sítio receptor, com ótimo suporte ósseo e um dente com rizogênese incompleta, pois há possibilidade de revascularização através do forame apical. Apesar do prognóstico do implante de dentes com rizogênese completa não ser tão favorável, existem relatos na literatura que documentam o sucesso desta técnica, vindo a ser mais uma alternativa de tratamento ${ }^{5}$.

A depender do grau de mobilidade após a adaptação do dente transplantado no alvéolo, a contenção pode ser realizada por meio de técnica flexível ou rígida. Tais contenções devem ser mantidas por um período variando entre 1 a 6 semanas $^{4,6}$. No entanto, há poucos estudos que relatam a influência da técnica flexível, utilizando-se de fios de sutura, sobre a contínua formação radicular em transplante de molares.

Frente à frequente necessidade da manutenção dos elementos dentários na cavidade bucal, seja por razões estéticas ou funcionais, o objetivo deste trabalho foi reportar um caso clínico de transplante dentário autógeno associado à contenção com fios de sutura e abordar os aspectos relacionados ao protocolo cirúrgico.

\section{RELATO DE CASO}

Paciente do gênero masculino, 16 anos, compareceu ao Hospital Universitário João de Barros Barreto, Belém, PA, Brasil, para consulta de rotina. Ao exame físico extraoral, o paciente não apresentava nenhuma deformidade facial. Na avaliação dentária apresentava clinicamente pericoronarite relacionada a 
elemento 38 e ao exame radiográfico panorâmico dos maxilares apresentava elemento 46 incluso em posição vestíbulo-lingual e provável dilaceração radicular (Figuras 1A-D).

Foi optado pela realização da exodontia do elemento 38 para tratamento da pericoronarite e exodontia do elemento $46 \mathrm{com}$ preparo deste alvéolo para subsequente transplante do elemento 38, devido ao alto índice de insucesso do tracionamento ortodôntico em dentes com dilaceração radicular avançada. Optou-se pela realização do transplante em sessão única, sob anestesia local e em ambiente ambulatorial do próprio hospital.

Para anestesia da região de molares inferiores foi efetuado um bloqueio regional dos nervos bucal, lingual e alveolar inferior utilizando como anestésico Mepivacaína HCL 2\% com Epinefrina 1:100 000 (Nova DFL Industria e Comercio S.A; Rio de Janeiro, RJ, Brasil). Realizou-se incisão pela técnica de envelope seguida da exodontia do elemento 46 e procedeu-se ao preparo do alvéolo desta região para posterior transplante, removendo-se o septo interradicular com Alvelótomo (Quinelato, Schobell Industrial Ltda, Rio Claro, SP, Brasil). Em seguida, exodontia do elemento 38. Ao ser transplantado, foi estabilizado com fio de nylon 4.0 (Pro Care Serviços de Saúde LTDA; São Paulo, SP, Brasil) na posição mais estável e em infra oclusão para evitar traumas precoces que pudessem interferir na cicatrização tecidual e reinserção das fibras periodontais (Figura 2A).

Foram prescritos antibiótico (amoxicilina $-500 \mathrm{mg}$ de $8 / 8$ horas por 7 dias), anti-inflamatório (nimesulida - $100 \mathrm{mg}$ de 12/12 horas por 3 dias), analgésico (dipirona sódica - $500 \mathrm{mg}$ de 6/6 horas por 2 dias) e solução de enxague (digluconato de clorexidina a $0,12 \%$ - 01 frasco de $8 / 8$ horas). O paciente foi orientado a manter uma boa higienização e ingerir alimentos líquidos ou pastosos, além da utilização de hidroterapia gelada em face protegida por 30 minutos de $3 / 3$ horas por dois dias. A sutura foi removida no sétimo dia pós-operatório, não sendo observados sinais clínicos de infecção.

Controles foram realizados em períodos de 1, 3, e 6 meses pós-operatórios, com realização de testes de vitalidade pulpar, avaliação da mobilidade dentária, exame de sondagem periodontal e exame radiográfico, sendo observadas condições de normalidade em todas as avaliações, ao verificar o dente hígido, estável no alvéolo, polpa vital e sem a presença de bolsas periodontais (Figuras 2B-E).

A partir de 6 meses de controle, o paciente foi submetido a tratamento ortodôntico, induzindo a movimentação dentária para correto posicionamento do primeiro molar inferior direito, a fim de atingir seu plano funcional. Dado o $12^{\circ}$ mês de controle clínico e radiográfico, ficou constatado que o dente transplantado para a posição de $1^{\circ}$ molar inferior direito possuía saúdes periodontal e pulpar, visto que apresentava vitalidade e ausência de bolsas periodontais e as imagens radiográficas sugerindo a continuidade da rizogênese no leito receptor (Figuras 3A-B).

\section{DISCUSSÃO}

Os transplantes dentários apresentam indicações muito específicas para alguns casos de anodontia parcial e como solução para perdas dentárias decorrentes de injúrias traumáticas, especialmente, em pacientes jovens. Nos adolescentes e adultos jovens, o desenvolvimento craniomandibular incompleto contra indica o uso de implantes e as soluções protéticas como

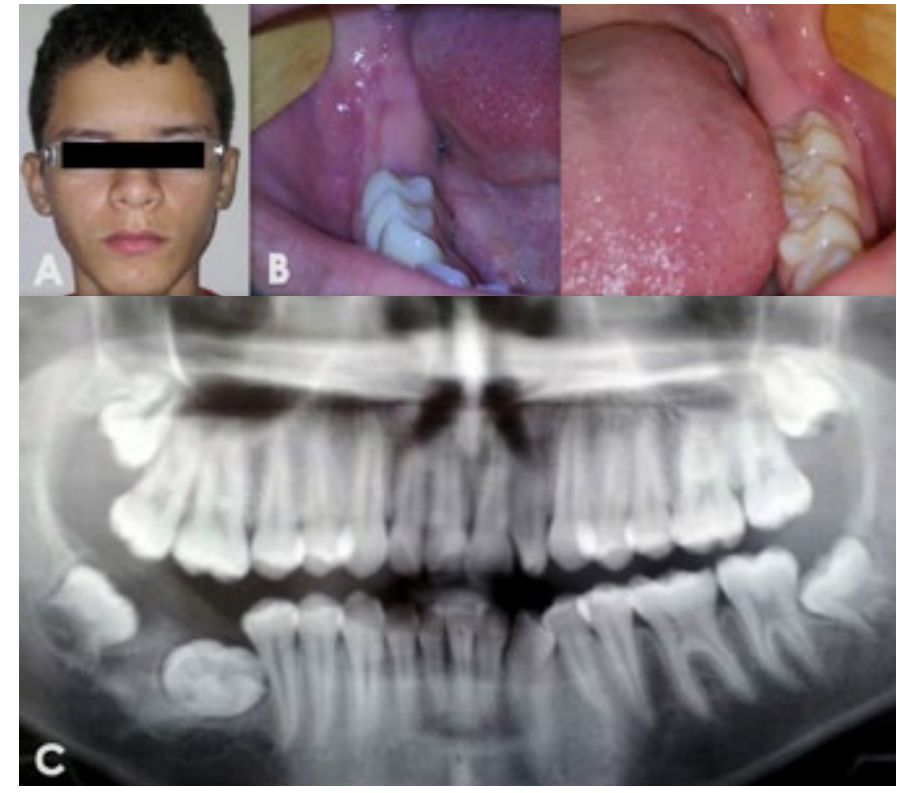

Figura 1 - A- Aspecto clínico extraoral inicial apresentando simetria facial. B- Aspecto clínico intraoral inferior. Mostrando elemento 46 não irrompido na cavidade oral e elemento 38 associado à pericoronarite. C- Radiografia panorâmica dos maxilares auxiliando no diagnóstico de dilaceração radicular (46) e inclusão (46 e 38).

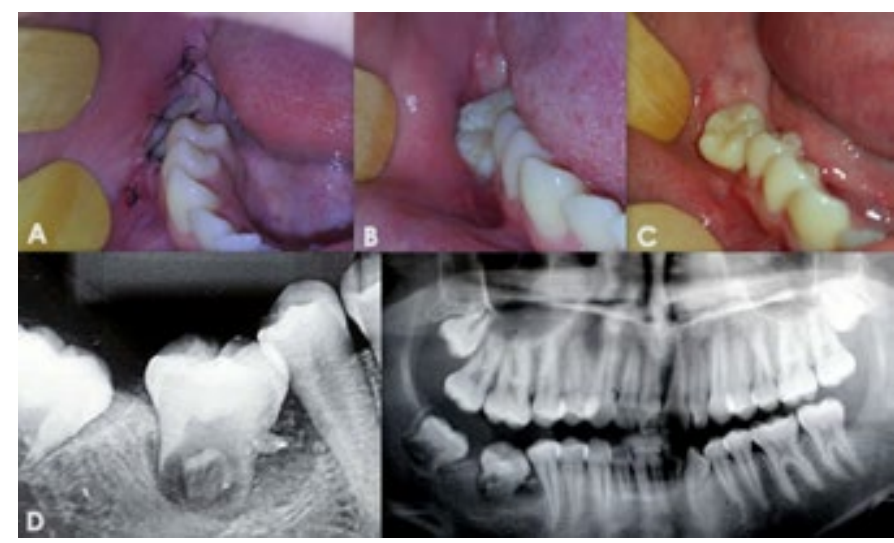

Figura 2 - A- Aspecto clínico da contenção com fio de sutura no elemento 38 transplantado para a região de primeiro molar inferior direito após 1 semana. B- Aspecto clínico no pós-cirúrgico de 1 mês C- Aspecto clínico no pós-cirúrgico de 6 meses D- Exames imagiológicos no pós-cirúrgico de 3 meses sugerindo continuidade da rizogênese no leito receptor e neoformação óssea.

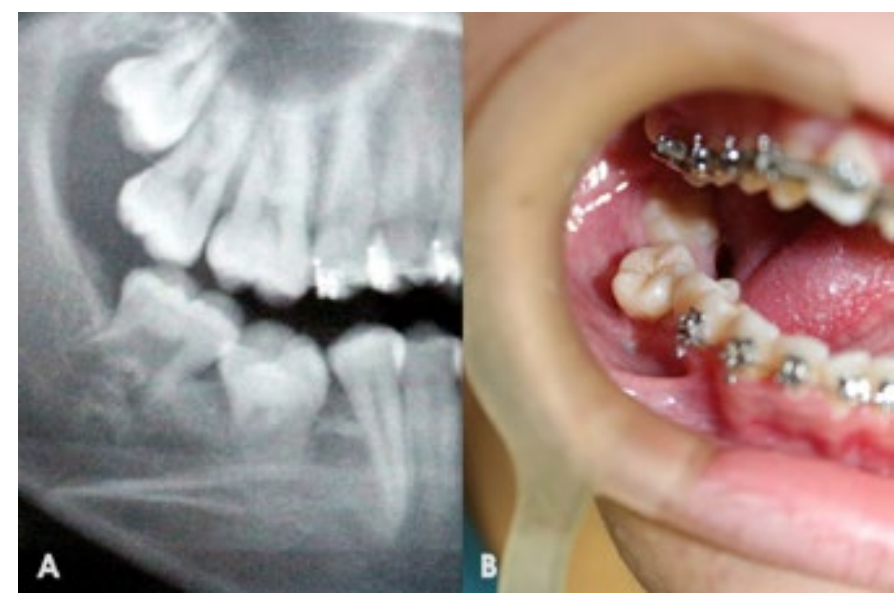

Figura 3 - Acompanhamento clínico e radiográfico no pós-cirúrgico de 1 ano. AObservar elemento ainda em infraoclusão (círculo), porém com erupção espontânea B- Paciente já se encontrava em tratamento ortodôntico. Elemento 38 transplantado foi observado sem mobilidade e com saúde periodontal. 
tratamento definitivo ${ }^{3,7}$, além de ter um alto custo em suas aquisições. A limitação dos transplantes dentários em relação aos implantes também está relacionada à disponibilidade de dentes dos pacientes que possam ser transplantados ${ }^{7}$.

A seleção dos pacientes é muito importante para o sucesso de autotransplante. Os candidatos devem apresentar boa saúde geral, higiene bucal, serem capazes de seguir as instruções pós-operatórias e disponíveis para acompanhamento periódico ${ }^{8}$. Além disso, os pacientes devem ter um sítio receptor e um dente doador viáveis para o autotransplante. A cooperação do paciente e compreensão são de suma importância para garantir resultados previsíveis ${ }^{4,8}$.

Observa-se na literatura que a criação de alvéolos para a transplantação dentária prejudica o desenvolvimento radicular pós-transplantação, sendo uma provável justificativa os danos à Bainha Epitelial de Hertwig. Mesmo que significativamente com menor diferença, a transplantação para alvéolos com recentes extrações, mostram-se mais favoráveis ao desenvolvimento radicular normal ${ }^{9}$. Neste caso, pela não acomodação adequada do transplante dentário em novo alvéolo, se fez necessária à utilização de instrumento cortante para realização de retirada do septo interradicular, para evitar uma nova etapa cirúrgica e que o dente ficasse fora do alvéolo sem nutrição adequada.

Kallu et al. ${ }^{6}$ (2005) analisaram retrospectivamente 273 dentes transplantados. Desses, 132 eram terceiros molares e observaram uma taxa de sucesso de $88 \%$, sendo o sucesso determinado pela ausência de qualquer tipo de reabsorção e/ou anquilose, razão coroa/raiz menor que um, evidência radiográfica de desenvolvimento radicular após a cirurgia, contorno gengival e profundidade de bolsa normais, mobilidade normal e sem sinais de inflamação. Estes fatores foram considerados preponderantes para o êxito da técnica utilizada nesse relato.

Em alguns poucos casos de dentes transplantados com rizogênese incompleta ocorre à necrose pulpar, providenciando-se de imediato o tratamento endodôntico. Nos casos de transplantes de dentes completamente formados o tratamento endodôntico quase sempre é requerido $\mathrm{o}^{4,10}$. A endodontia não foi requisitada neste relato, porém o acompanhamento periódico foi de essencial para verificação de sua necessidade.

Para os dentes transplantados com diferentes estágios de desenvolvimento radicular, a literatura demonstra que os melhores resultados obtidos, ou seja, a maior taxa de sucesso a médio/ longo prazo são aqueles que se encontram entre $1 / 2$ a $3 / 4$ do comprimento radicular ${ }^{1-2,6-7}$.

Um estudo, previamente publicado, constatou que o tipo de contenção rígida, utilizando-se de splintagem por longo período, gera efeitos negativos no comprimento radicular final, nas cicatrizações dos tecidos pulpar e periodontal em transplantes de molares com rizogênese incompleta ${ }^{10}$. Ao comparar com o método de fixação flexível (fio de sutura), verificou-se que este não influencia negativamente sobre a fase de desenvolvimento radicular, sendo seu uso indicado nesse tipo de cirurgia, apesar de haver relatos de falha na estabilidade inicial em seu empre$\mathrm{go}^{5,10}$. No presente estudo, foi preconizada a contenção flexível com fio de sutura, pois imediatamente a transplantação foi observada adaptação satisfatória do dente no novo alvéolo, sendo dispensável a utilização de fios de aço associados à resina ou cimento cirúrgico.
A literatura disponível também demonstra que, em uma situação ideal, um dente poderá responder positivamente aos testes de sensibilidade e mobilidade num período máximo de 6 meses ${ }^{4}$. No caso clínico aqui apresentado, o paciente foi submetido aos testes no período de 1, 3, 6 e 12 meses de pós-cirúrgico e sempre resultados positivos foram observados. Ou seja, o dente transplantado apresentava-se estável e com vitalidade pulpar.

Quando um dente for transplantado e cirurgicamente for respeitado o princípio biológico de preservação dos tecidos periodontais e foliculares aderidos à raiz em formação, o mesmo apresentará estruturas radiculares normais, tal como um dente não transplantado. Como um dente normal, os dentes transplantados podem apresentar as mesmas consequências da movimentação dentária induzida, especialmente reabsorções radiculares. Desta forma os dentes transplantados podem receber tratamentos estéticos e ortodônticos habituais ${ }^{7}$. A ortodontia foi solicitada para este caso pela necessidade de posicionamento correto do transplante dentário.

Alguns dos fatores que levam ao sucesso da técnica têm sido extensivamente investigados. $\mathrm{O}$ determinante mais importante para a sobrevivência do transplante é a manutenção da vitalidade da membrana periodontal. Dentre casos em que o ligamento periodontal é traumatizado durante a transplantação, a reabsorção radicular externa e a anquilose são muitas vezes observados. A experiência do cirurgião também afeta o sucesso, porque este procedimento é sensível à técnica ${ }^{8}$. Além da utilização de contenções, que a depender das indicações, podem prejudicar a formação radicular ${ }^{10}$.

\section{CONCLUSÕES}

A reabilitação oral realizada através de transplantes dentários autógenos constitui um método eficaz e de baixo custo, comparado a tratamentos definitivos como a reabilitação protética e uso de implantes.

\section{REFERÊNCIAS}

01. Yadav, SS, Bodh R, Kaushik A, Talwar S. Autotransplantation of a buccally erupted matured mandibular third molar to replace a grossly decayed second molar. J Clin Diagn Res. 2016; 10(2): ZD06-ZD07.

02. Peixoto AC, Melo AR, Santos TS. Transplante dentário: atualização da literatura e relato de caso. Rev Cir Traumatol Buco-Maxilo-Fac. 2013; 13(2): 75-80.

03. Pacini NM, Nery DTF, Carvalho DR, Junior AF, Macedo SB Dental autotransplant: case report. RSBO. 2012; 9(1): 108-13.

04. Mejàre B, Wannfors K, Jansson L. A prospective study on transplantation of third molars with complete root formation. Oral Surg Oral Med Oral Pathol Oral Radiol Endod. 2004; 97(2): 231-8.

05. Sugai T, Yoshizawa M, Kobayashi T, Ono K, Takagi R, Kitamura N, et al. Clinical study on prognostic factors for autotransplantation of teeth with complete root formation. Int J Oral Maxillofac Surg. 2010; 39(12): 1193-203.

06. Kallu R, Vinckier F, Politis C, Mwalili S, Willems G. Tooth transplantations: a descriptive retrospective study. Int $\mathrm{J}$ Oral Maxillofac Surg. 2005; 34(7): 745-755.

07. Consolaro A, Pinheiro TN, Intra JBG, Roldi A. Transplantes dentários autógenos: uma solução para casos ortodônticos e uma casuística Brasileira. Rev Dent Press Ortodon Ortop Facial. 2008; 13(2): 23-28. 
08. Silva MHC, Lacerda MFLS, Chaves MGAM, Campos CN. Autotransplantation of a mandibular third molar: A case report with 5 years of follow-up. Braz Dent J. 2013; 24(3): 289-294.

09. Bauss O, Zonios I, Rahman A. Root development of immature third molars transplanted to surgically created sockets. J Oral Maxillofac Surg. 2008; 66(6): 1200-1211.
10. Bauss O, Engelke W, Fenske C, Schilke R, Polly RS. Effect of different splinting methods and fixation periods on root development of autotransplanted immature third molars. J Oral Maxillofac Surg. 2005; 63(3):304-310.

\section{ABSTRACT}

Objective: To report a clinical case of autogenous dental transplantation associated to contention with suture thread and description of the surgical steps. Materials and methods: An individual submitted to lower third molar transplantation for a lower first molar alveolus with compromised eruption by advanced root laceration, through exodontia by the envelope incision technique, followed by containment with a suture thread during a week. Results: The transplanted tooth obtained satisfactory accommodation in the new alveolus: during 1-year follow-up, the tooth presented rhizogenesis, absence of periodontal pockets, pulp abnormality and lack of dental mobility. Conclusions: Over the surgical technique used and appropriate indications, it was considered the low cost and biologically viable therapy - for not compromising the root formation - as a solution in case of oral rehabilitation.

Keywords: Transplantation Autologous; Tooth Extraction; Surgery Oral; Maxilla.

\section{AUTOR PARA CORRESPONDÊNCIA}

Rafael Quadros Lopes da Silva

Hospital Universitário João de Barros Barreto

Rua dos Mundurucus, 4487, Cep: 66073-000, Belém/Pará

E-mail: raloquasi@hotmail.com 